\title{
A Comunicação política das micromobilizações na internet a partir da observação do hip hop em Curitiba ${ }^{1}$
}

Kelly Prudencio e José Geraldo da Silva Junior

\section{Resumo}

0 artigo apresenta uma perspectiva de análise para mobilizações políticas na internet, baseada na teoria da mobilização política ou dos processos políticos (McAdam, McCarthy e Zald, 2008; Tarrow, 2009, Gamson, 1990), especificamente dos processos de interação entre atores nesse ambiente. Com ela, a intenção é oferecer algum subsídio teórico para a observação de fenômenos semelhantes, apresentando um exemplo a partir das micromobilizações na internet pelos grupos e indivíduos ligados ao hip hop em Curitiba. Entendemos que o processo de enquadramento da ação coletiva nas mídias digitais se constitui um trabalho de comunicação política, na medida em que desenha internamente aos quadros da mobilização o que deve ser apresentado publicamente como demanda coletiva.

\section{Palavras-Chave}

Mobilização política. Enquadramento.

Internet. Hip hop.
Kelly Prudencio I kelly.prudencio5@gmail.com Doutora em Sociologia Política. Professora no Departamento de Comunicação da Universidade Federal do Paraná. Coordenadora do grupo de pesquisa Comunicação e mobilização política (CNPq/UFPR). Em pós-doutorado no Programa de Pós-Graduação em Comunicação Social da Universidade Federal de Minas Gerais.

\section{José Geraldo da Silva Junior}

I jota_geraldo@hotmail.com

Mestre em Comunicação pelo Programa de Pós-Graduação em Comunicação da UFPR, pesquisador no grupo de pesquisa Comunicação e mobilização política (CNPq/UFPR).

\section{Introdução}

A onda de protestos que vêm ocorrendo desde 2011 em diferentes países, incluindo o Brasil, tem feito proliferar muita celeuma, mas muito pouco esclarecimento sobre o significado, causas e consequências de tais acontecimentos. Grande parte das informações e opiniões sobre os protestos circula na internet. Anos de pesquisa na área de internet e política não foram capazes de combater o determinismo tecnológico presente na crença de que a mobilização política só foi possível principalmente pela presença de dispositivos digitais de compartilhamento de informações nas chamadas redes sociais.

Pretendemos aqui propor uma perspectiva de análise baseada na teoria da mobilização política ou dos processos políticos (MCADAM, McCARTHY e ZALD, 2008; TARROW, 2009, GAMSON, 1990; JOHNSTON, 2011), especificamente quando tratam dos processos de "alinhamento de quadros". Com ela, a intenção é oferecer algum subsídio teórico para a observação de tais fenômenos, apresentando 
um exemplo a partir das micromobilizações na internet pelos grupos e indivíduos ligados ao hip hop em Curitiba.

\section{Mobilização de quadros da/para a ação coletiva}

A literatura consultada sobre enquadramento (GOFFMAN, 2012; MENDONÇA \& SIMÕES, 2012; CAMPOS, 2013) apresenta Gregory Bateson como precursor da utilização do termo "quadro" (frame) com sentido semelhante ao que 0 conceito assumiu ao longo da segunda metade do século XX até hoje. Acionando o termo "quadro" de Bateson e articulando com o pensamento de autores como William James, Alfred Schütz, Harold Garfinkel e John Austin, Erving Goffman (2012, p.30) colocará que "quando os indivíduos se interessam por qualquer situação social usual, eles se confrontam com a pergunta: ' 0 que é que está acontecendo aqui?"”. ${ }^{2}$

Neste contexto, empregará o conceito de quadro para se referir a esses princípios que possibilitam que os sujeitos definam a situação em que se inserem e como se posicionar perante ela, derivando desta reflexão a expressão "análise de quadros" para designar 0 exame da organização da experiência.
A partir dessa matriz, Mendonça \& Simões (2012) identificam três vertentes de "análise de enquadramento":

\section{1) Análise da situação interativa: os} estudos desta vertente partem do conceito de enquadramento para a microanálise de interações sociais. Os pesquisadores mencionam Daniel Cefaï, pesquisador que procura compreender o legado de Goffman na esfera da sociologia da ação coletiva. Para CEFAÏ, $\left(2007^{3}\right.$, p. 626 apud MENDONÇA \& SIMÕES, 2012, p.192)

[...] os acontecimentos práticos e discursivos que ocorrem no mundo vivido dos indivíduos, as situações que os afetam, convocam-nos a interagir e a se unir em um coletivo. 0 alinhamento das operações de enquadramento é, então, estudado nos lugares e nos momentos de copresença, sem que seja perdida sua dinâmica temporal e interacional in situ.

2) Análise de conteúdo discursivo: esta vertente de estudos mobiliza o conceito de enquadramento para análises de conteúdo. Diferentemente da primeira vertente, 0 foco recai sobre o próprio conteúdo dos discursos e não sobre a situação ou contexto pragmático da interação. A intenção é compreender

Este artigo apresenta parte dos resultados da pesquisa "Mapeamento e repertório do ativismo digital brasileiro", financiada pelo CNPq. Uma versão deste texto foi apresentada no Grupo de Trabalho Comunicação e Política do XXIII Encontro Anual da Compós, na Universidade Federal do Pará, Belém, de 27 a 30 de maio de 2014.

20 conceito de "definição da situação" foi elaborado por William Thomas e Florian Znaniecki, no livro The polish peasant in Europe and America, de 1919.

CEFAï, Daniel. "Pourquoi se mobilise-t-on? Lês thérories de l'action collective”. Paris, La Découverte/M.A.U.S.S, 2007. 
o modo como discursos estabelecem molduras de sentido, enquadrando 0 mundo a partir de perspectivas específicas buscando "pensar a maneira como o próprio conteúdo discursivo cria um contexto de sentido, convocando os interlocutores a seguir certa trilha interpretativa" (MENDONÇA \& SIMÕES, 2012, P.193).

\section{3) Análise de efeito estratégico: esta} vertente toma o conceito de enquadramento como um ângulo discursivo estrategicamente mobilizado por determinado ator social para produzir certos efeitos (framing effects).

Ao contrário da segunda vertente, nesta os quadros não são entendidos como molduras de sentido partilhadas e discursivamente mobilizadas. Elas se tornam estratégias de construção de proferimentos para gerar determinados efeitos. "Frames são, aqui, um viés construído pelo enunciador" (IDEM, p.195).

A reflexão em torno destas três vertentes chama a atenção pelo fato da discussão em torno da aplicação do conceito de enquadramento em pesquisas sobre movimentos sociais (SNOW et al, 1986; McADAM; McCARTHY; ZALD, 1996; SNOW \& BENFORD, 2000) ficar em segundo plano, em detrimento das pesquisas que têm como foco os enquadramentos no contexto dos meios de comunicação, as quais ocupam posição privilegiada na reflexão proposta pelo texto.
A discussão da primeira vertente esboça essa possibilidade no plano teórico com a menção às pesquisas sobre ação coletiva encampadas pelo sociólogo Daniel Cefaï, mas quando cita exemplos empíricos, o faz com casos de enquadramento no contexto da televisão. Na segunda vertente, os autores destacam a dimensão política dos frames, visto que eles "podem definir problemas, diagnosticar causas, fazer julgamentos morais e sugerir soluções" (MENDONÇA \& SIMÕES, 2012, P.193), mas, novamente, o foco recai sobre os enquadramentos midiáticos e apenas resvala nas pesquisas sobre movimentos sociais com a citação de Gamson (1992), que elenca três tipos de enquadramento mobilizados em batalhas simbólicas: frames de injustiça, frames de agência eframes de identidade.

Deste modo, embora a primeira e segunda vertentes contemplem elementos que possam ser aproximados a determinadas práticas de construção de ação coletiva, propõe-se acrescentar às vertentes apresentadas uma quarta, que tem nos processos de mobilização seu universo analítico. Nesse sentido, entendese que 0 processo de mobilização tem seu fundamento na comunicação dos quadros da ação coletiva.

A intenção é observar as interações entre ativistas, sejam eles ligados a movimentos sociais, sejam eles pessoas que se tornam ativistas a partir do surgimento de causas específicas e, às vezes, temporárias, em espaços na internet, 
com foco nos enquadramentos produzidos em atividades de micromobilização, as quais servem, em um primeiro momento, para a estabilização de quadros da ação coletiva no âmbito do núcleo gerador da ação coletiva e, em um segundo momento, para sustentarem ações coletivas com outros atores da sociedade civil, das instituições políticas e dos meios de comunicação. Chamaremos essa vertente de análise de mobilização de quadros.

Snow et al (1986, p.476) propõem uma análise de "alinhamento de quadro" como uma ponte conceitual, capaz de conectar simultaneamente reflexões da psicologia social e reflexões de ordem estrutural/organizacional às pesquisas sobre participação em ações coletivas.

Para estes autores, o que está em questão nos processos de mobilização não é apenas a presença ou a ausência de queixas, mas a maneira com que estas queixas são interpretadas e como estas interpretações são generalizadas e difundidas, o que nos leva a considerar que a mobilização é um processo fundamentalmente de comunicação política.

0 "alinhamento de quadro" é apresentado como a ligação dos indivíduos às orientações interpretativas do que estes autores denominam "organizações de movimentos sociais (OMSs)", de modo que interesses, valores, crenças individuais e atividades sejam congruentes e complementares às metas das organizações.
Esta formulação advém do entendimento de que a interpretação comum dos problemas é particularmente relevante para compreender a operação dos movimentos sociais e a geração de apoio e participação nas suas atividades. Assim, no cerne desta perspectiva, que compreende que os quadros servem para organizar a experiência e guiar a ação tanto no plano individual como no plano coletivo, o "alinhamento de quadro" é assentado como condição necessária para a participação do indivíduo em um movimento, seja qual for sua natureza ou intensidade.

Ainda segundo estes autores, existem quatro tipos de processos de alinhamento de quadros: frame bridging; frame amplification; frame extension; frame transformation.

Frame bridging é a ligação de dois ou mais quadros congruentes, mas ideologicamente desconectados a respeito de um determinado assunto ou problema. Frame amplification refere-se ao esclarecimento e fortalecimento de um quadro interpretativo sobre um determinado assunto, problema ou conjunto de eventos.

0 frame extension pode ser explicado pela expansão das fronteiras do quadro principal (primary framework), protagonizada por uma OMS de forma a englobar interesses ou pontos de vistas que nem sempre correspondem aos seus objetivos primários, mas que possuem considerável relevância para potenciais adeptos. Esta expansão é necessária quando determinados valores ou sentimentos promovidos por uma OMS 
encontram nenhuma ou pouca correspondência nas vidas e/ou interesses de adeptos em potencial. Já oframe transformation referese a um processo de alinhamento de quadro baseado em um novo quadro que interpreta os acontecimentos e as experiências em uma nova chave. Neste processo de alinhamento de quadro, algo que era percebido como problemático, mas era tolerado passa a ser enquadrado como indefensável, injusto e imoral.

Entende-se então, pensando com Snow \& Benford (2000), que seja no âmbito do núcleo de um movimento, seja entre o movimento e a sociedade civil, a construção, definição e consolidação dos quadros da ação coletiva dependem de: a) como os atores negociam um entendimento compartilhado de que uma situação ou condição é problemática e passível de mudança; b) definem problemas e culpados; c) articulam um conjunto alternativo de medidas e estimulam outros a agir em prol da mudança.

Os autores apresentam três conceitos para definir as operações que acontecem no núcleo dos processos de enquadramento orientados para a ação coletiva: enquadramento de diagnóstico, enquadramento de prognóstico e enquadramento motivacional. 0 primeiro refere-se à identificação de problemas e identificação do adversário; 0 segundo envolve a articulação de uma proposta de solução para o problema, ou, pelo menos, estratégias para realização do plano; e o terceiro visa motivar ações para a realização de mudanças.
Snow \& Benford (2000, p.623) destacam

ainda os processos discursivos na formação dos quadros da ação coletiva. Os processos discursivos referem-se às interações orais ou escritas entre ativistas. São estas articulações que, ao promoverem 0 alinhamento de diferentes quadros interpretativos, possibilitam a emergência dos quadros da ação coletiva, primeiro entre os próprios atores do movimento e depois, já em uma situação de mobilização política, entre o movimento e possíveis apoiadores que poderão ou não assumir para si as questões do movimento na forma em que elas lhes aparecem enquadradas.

\section{Mobilização política na internet}

De acordo com Tarrow (2009, p. 165), a partir da segunda metade do século XX, muitos movimentos sociais aprenderam a "tirar vantagem de alguns avanços na comunicação (...) e preparar e coordenar a ação coletiva através de uma grande extensão de territórios em competição com os partidos, grupos de interesse e governos".

Aprofundando este debate, McAdam, Tilly \& Tarrow (2009) falam no aparecimento de novas formas de ação coletiva propiciadas pela globalização e pela navegação livre na internet. "Onde a comunicação eletrônica se torna um meio para propagar informações de movimentos, há uma maior capacidade de as pessoas em todo 0 mundo ganharem mais poder com pouco risco" (MCADAM, TILLY, TARROW, 2009, p.41). 
Os pesquisadores chamam a atenção para 0 fato de que as instituições transnacionais emergentes ou uma expansão da capacidade de comunicação não necessariamente criam movimentos transnacionais. Por outro lado, reconhecem que são capazes de fornecer novas oportunidades e maiores recursos que podem transformar as redes sociais nativas em movimentos sociais nacionais.

Prudencio (2012) destaca que os populares sites de relacionamento têm sido cada vez mais associados a práticas de ativismo político por facilitar o protesto à distância e mobilizar pessoas a produzirem manifestações presenciais. A autora adverte, todavia, que, embora haja reconhecimento de uma certa força (ou velocidade) de mobilização, ainda é preciso observar quais elementos compõem tais ações, para que não se retorne à defesa irrefletida da internet como redentora dos grupos ativistas. Em artigo sobre a Marcha das Vadias de Curitiba, Silva Jr. (2013) evidencia que a utilização da internet esteve aliada a processos de mobilização face a face no espaço público, o que constitui uma prática efetiva em ações de mobilização política.

Elencando uma série de estudos que variam entre a percepção da internet e seus recursos como capazes de aumentar a participação democrática, fortalecer as organizações da sociedade civil e revigorar a democracia, até estudos que, além das potencialidades da internet, apontam limitações, Maia (2011, p. 69) entende que "a internet não promove automaticamente a participação política e nem sustenta a democracia", o que, segundo a autora, não significa que a internet seja tão somente uma infraestrutura neutra nem que não potencialize alterações entre aqueles que a utilizam com propósitos políticos.

Em artigo sobre os rappers de Curitiba, Prudencio \& Silva Jr. (2013) expõem que muitos destes atores sociais utilizam a internet para interagir e mobilizar parceiros e simpatizantes para ações estéticas e políticas que comunicam no espaço público uma luta por reconhecimento. Ainda de acordo com os pesquisadores, essas ações, transformadas em registros audiovisuais ${ }^{4}$, são posteriormente veiculadas em mídias sociais administradas por eles, gerando, com isso, novas interações, cuja circularidade ajuda os grupos de rappers a manter-se em movimento, enquanto suas reivindicações por políticas públicas culturais mais abrangentes não são formuladas pelos organismos governamentais responsáveis pela gestão cultural do município e do Estado.

Assim, as mídias sociais digitais, fóruns e salas de bate-papo constituem um espaço para acompanhar a "micromobilização" - termo cunhado por Snow et al (1986, p.465) para se referir "ao conjunto de processos interativos elaborados e empregados pelas OMS e por seus representantes para mobilizar ou influenciar outros grupos na busca de interesses coletivos ou comuns". 
Quase três décadas depois da publicação do artigo, além das 0MSs, observa-se a emergência de outras formas de ação coletiva mais fluidas, 0 que se deve em larga medida pela consolidação de práticas de ação coletiva com a utilização de tecnologias digitais. "A internet e outras mídias digitais têm facilitado a organização de redes com estruturas flexíveis; (...) redes que se formam através de amplas coalizões com vínculos horizontais e conexões entre elementos autônomos diversos" (MAIA, 2011, p.74). Sendo assim, o conceito de micromobilização pode ser estendido às novas formas de mobilização política sem prejuízo à sua formulação original relacionada às 0MSs.

Com as tecnologias digitais, o leque de estruturas de mobilização se amplia. Já os processos de mobilização não foram alterados radicalmente, continuando dependentes de processos de interação e comunicação, seja face a face, seja à distância por intermédio de dispositivos tecnológicos.

0 que está em jogo nestas micromobilizações é o próprio sentido de determinados aspectos da realidade social para os atores envolvidos e a possibilidade de exercer influência sobre eles. Atuando sobre este sentido, está o trabalho de alinhamento de quadros que ativistas operacionalizam na tentativa de tornarem comuns, ou melhor, comunicar seus "quadros da ação coletiva" (collective action frames), os quais abarcam conjuntos de crenças e significados e são capazes de inspirar e legitimar nos indivíduos 0 impulso do agir coletivo (SNOW \& BENFORD, 2000, p.614).

Essa discussão não alcança a complexidade dos conceitos de enquadramento e mobilização, mas permite operar uma análise qualitativa de quadros em processos de micromobilização social durante interações em mídias sociais, fóruns de internet e salas de bate-papo.

\section{Por dentro do movimento}

A proposta de observação e análise de micromobilizações na internet se configura, na verdade, como um conjunto de condições para identificação de processos de alinhamento de quadros, com vistas à comunicação política dos mesmos.

\section{A proposta então está baseada nos seguintes aspectos:}

1) Que seja possível encontrar na micromobilização uma união em torno de uma campanha específica ou para as causas do próprio movimento; se ela ocorre apenas na internet e em que espaço da internet está ocorrendo; quem são os protagonistas e se é possível identificar quem está mobilizando e quem está sendo mobilizado.

2) A identificação de "oportunidades políticas" ${ }^{\circ}$ menções a crenças, ideologias, significados comuns, práticas, 
valores, mitos, narrativas, definição

de um "nós" e de um "eles" (público de referência) no discurso do ator que protagoniza a mobilização.

3) 0 reconhecimento de quadros da ação coletiva formulados pelo perfil do movimento ou de um representante deste durante os processos interacionais e comunicacionais que emergem ao longo do seu trabalho de micromobilização e posterior classificação desses quadros em "quadros motivacionais", "quadros de prognóstico" e "quadros de diagnóstico".

4) A sistematização de argumentos, proposições, contextualizações, associações a fatores socioculturais conhecidos, menções a crenças, valores e ideologias, indicações de "oportunidades políticas" distintas acionadas para colocá-los em ação.

5) 0 agrupamento dos atores pelos quadros identificados nas interações.

6) A explicitação dos processos de alinhamento de quadros, a partir dos quatro tipos (frame bridging, frame amplification, frame extension eframe transformation).
7) A construção analítica dos processos de enquadramento que foram forjados no decorrer da micromobilização. Entendemos que é possível, assim, demonstrar que essas micromobilizações podem ou não desenvolver o alinhamento de quadros, que diagnóstico, prognóstico e motivação para a ação constituem um trabalho de comunicação passível de desentendimentos, retrocessos e nem sempre apontam para a solução do problema enquadrado primariamente.

A seguir, é apresentado um exemplo de aplicação sobre uma interação ocorrida no contexto do movimento hip-hop de Curitiba, na qual há um direcionamento da ação ou um alinhamento de quadros, a partir da percepção de uma oportunidade política no âmbito da política cultural local.

\section{Hip-hop entre o confronto e 0 alinhamento estratégico}

0 hip-hop em Curitiba não é um movimento unificado. Seus atores distribuídos em coletivos, grupos, selos/gravadores e crews constroem, na maior parte do tempo, ações independentes de uma organização de movimento social delimitada. Em determinadas circunstâncias, contudo, 
membros destes grupos se encontram no território urbano e na internet e participam da mesma ação que pode ser, por exemplo, um show, um abaixoassinado, uma discussão nas mídias sociais sobre os rumos da cultura hip-hop, uma rodada de negociação com os órgãos municipais e estaduais de gestão cultural.

A interação que será analisada e que pode ser lida como um processo de micromobilização ocorreu no Facebook entre um representante de um grupo do hip-hop com certo conhecimento dos trâmites institucionais para obtenção de recursos junto aos órgãos públicos de gestão cultural na cidade (A) e um grupo mais preocupado em publicizar seu descontentamento (B).

Nesta micromobilização, A procura estimular B a adotar uma postura mais estratégica em relação aos órgãos públicos de financiamento.

Em março de 2013, B criou 0 abaixo-assinado ${ }^{6}$ eletrônico "Quero Rap na Virada" introduzindo-0 com 0 seguinte texto:

Esta campanha é para você que já está cansado de não ouvir a música que lhe representa no Festival de Cultura denominado "Virada Cultural" que aconteceu nos últimos 3 anos na sua própria cidade, Curitiba. Por este motivo nós convocamos vocês, para exigir que o RAP seja representado em um dos shows principais do evento. Para isso iremos desenvolver um abaixo-assinado online, para mostrarmos a força que a periferia representa na cidade de Curitiba. Chamem seus amigos, chamem seus vizinhos! ASSINEM 0 ABAIXO-ASSINADO, e vamos conquistar nosso espaço.

Ao ser divulgado no Facebook, o documento despertou algumas reações, entre elas a de A, próximo a um conjunto de atores que está procurando dialogar diretamente com o poder público. A postou uma longa mensagem com diversos elementos que indicam que este grupo defende uma aproximação estratégica do hiphop ao poder público e, para tanto, constrói enquadramentos e processos de alinhamento de quadros com o intuito de consolidar no mundo heterogêneo do hip-hop local uma ação coletiva unificada.

Com todo respeito rapaziada não sei quem criou o tópico... Fico muito feliz em vê-los movimentando para isso, mas estão tomando o caminho errado. 0 problema da virada cultural é 0 mesmo do aniversário de Curitiba. NINGUÉM do hip-hop se inscreveu para participar. Todo ano eles abrem editais para Virada Cultural e cadastro dos artistas. E NUNCA ninguém do hip-hop vai lá e apresenta o projeto conforme a lei pede. Esse abaixo assinado só vai resultar em uma resposta: "quando abrirem o edital vocês inscrevem o trabalho de vocês". Falo isso porque já fui lá dentro do sistema e vi como funciona. Se querem realmente que nos respeitem

0 abaixo-assinado foi disponibilizado no seguinte endereço da web <<http://www.abaixoassinado.org/assinaturas/ assinar/10800 >>. Acesso em: Mar. 2013.

A Virada Cultural é o evento que encerra a Corrente Cultural, uma série de shows com artistas locais e nacionais. A Corrente Cultural, de acordo com o site da Fundação Cultural de Curitiba, "é fruto da união de instituições públicas e privadas, artistas e produtores culturais, em torno de um mesmo objetivo: valorizar e promover a diversidade cultural em Curitiba". Informação disponível em: << http://www.fundacaoculturaldecuritiba.com.br/grandes-eventos/corrente-cultural/>>. Acesso em 1 Jun.2013. 
temos que falar a língua deles, ou seja, fazer projetos. Existem vários cursos de capacitação para escrever projetos para o governo. É um caminho extremamente chato, mas é a regra. Minha maior frustração foi ver um dos responsáveis pelos shows do aniversário de Curitiba dizer bem assim pra mim: "depois os caras do hip-hop reclamam do espaço, mas ninguém se inscreveu" Fiquei muito triste com isso. Eu não tenho música pra fazer show, mas sempre que posso tento escrever um projeto e conseguir um aval do governo. Prova disso foram alguns eventos que fizemos ano passado. Conquistar nosso espaço é um caminho difícil com regras que foram feitas para a gente desistir. 0 Prêmio Paraná Hip Hop eles querem que a gente insira na Virada Cultural. Ou seja, eles querem a gente lá. Ou melhor, eles precisam da gente lá. Mas para isso vamos ter que falar a língua deles: "projetos burocráticos".

Nesta postagem de A, é possível observar a tentativa de comunicar a existência de uma "oportunidade política" no contexto dos órgãos institucionais responsáveis pela gestão cultural. Para definir esta situação, constrói dois enquadramentos com termos usuais entre os adeptos do hip-hop e, portanto, facilmente reconhecíveis por eles. Dentre os quadros resultantes desta ação, pode-se elencar: "lá dentro do sistema" e "temos que falar a língua deles".

No contexto da postagem "falar a língua deles" significa adequar as reivindicações do movimento aos procedimentos-padrão dos órgãos públicos municipais e estaduais responsáveis pela administração dos recursos de fomento à cultura. Significa também apresentar-se aos órgãos culturais e a seus representantes com uma imagem distinta dos atores coletivos do movimento, ou seja, uma imagem de movimento cultural organizado e que conhece as práticas institucionalizadas. Para isso, ao invés de abaixoassinados, devem ser feitos projetos culturais.

Diante disso, pode-se dizer que, em um contexto de burocratização da cultura, "falar a língua deles" e "dentro do sistema" assumem um significado que comunica a possibilidade de obter recursos do município por meio do aprendizado dos trâmites legais dos editais públicos, o que implica treinamento, participação em cursos, acompanhamento sistemático de editais e construção coletiva de projetos.

Simultaneamente, verifica-se a formação de um campo de confronto que se dá por intermédio da definição de um "nós" oprimido, desafiante e de um "eles", detentor do poder de definir regras que limitam o desenvolvimento do movimento e dos seus atores. "Conquistar nosso espaço é um caminho difícil com regras que foram feitas para a gente desistir. 0 Prêmio Paraná Hip Hop eles querem que a gente insira na Virada Cultural. Ou seja, eles querem a gente lá. Ou melhor, eles precisam da gente lá. Mas para isso vamos ter que falar a língua deles: 'projetos burocráticos"”.

Por meio da criação de um nós e de um eles, 0 A tenta demonstrar a B que estão do mesmo lado. A comunicação do grupo A é construída como se houvesse um só movimento hip-hop na cidade e não movimentos de movimentos que ora se aproximam, ora se distanciam. 
Outro ponto interessante é a transmissão de saberes e experiências acumuladas pelo Grupo A que, além de operar no processo de enquadramento para a construção de uma ação coletiva construída de acordo com as regras da burocracia cultural, serve para que o grupo B reflita sobre suas práticas.

Pode-se dizer que o quadro da ação coletiva que está sendo formulado por A se relaciona com uma predisposição de negociar com o poder público partir da percepção de uma oportunidade política existente no âmbito dos órgãos de gestão cultural, que é a possibilidade do movimento participar efetivamente dos processos de distribuição de recursos.

Esta discussão simplificada pelas construções "falar a língua deles" e "lá dentro do sistema" delimita uma série de questões complexas, como capacitação técnica, acompanhamento de editais, elaboração de projetos, que definem quem são os "detentores do poder" e quem são os "desafiantes" e são encaminhadas para a apresentação do que pode se entender como um "quadro de ação coletiva", ou seja, "projetos burocráticos", cuja operacionalização é feita por A de modo a tornar o termo menos distante do universo cultural de $\mathbf{B}$, bem como de forma que não signifique uma "rendição ao sistema".

Em suma, "projetos burocráticos" é o quadro através do qual A procura mobilizar $\mathbf{B}$, por meio de um processo de alinhamento de quadros. Assim, A realiza no núcleo desta construção as três operações de que falam Snow \& Benford (2000): a) Quadro de diagnóstico: "NINGUÉM do

hip-hop se inscreveu para participar. Todo ano eles abrem editais para Virada Cultural e cadastro dos artistas. E NUNCA ninguém do hip-hop vai lá e apresenta o projeto conforme a lei pede. Esse abaixo assinado só vai resultar em uma resposta: 'quando abrirem 0 edital vocês inscrevem 0 trabalho de vocês'. Falo isso porque já fui lá dentro do sistema e vi como funciona".

b) Quadro de prognóstico: "Se querem realmente que nos respeitem temos que falar a língua deles, ou seja, fazer projetos. Existem vários cursos de capacitação para escrever projetos para o governo. É um caminho extremamente chato, mas é a regra".

c) Quadros motivacionais: "Minha maior frustração foi ver um dos responsáveis pelos shows do aniversário de Curitiba dizer bem assim pra mim: 'depois os caras do hip-hop reclamam do espaço, mas ninguém se inscreveu' Fiquei muito triste com isso. Eu não tenho música pra fazer show, mas sempre que posso tento escrever um projeto e conseguir um aval do governo. Prova disso foram alguns eventos que fizemos ano passado. Conquistar nosso espaço é um caminho difícil com regras que foram feitas para a gente desistir. 0 Prêmio Paraná Hip Hop eles querem que a gente insira na Virada Cultural. Ou seja, eles querem a gente 
lá. Ou melhor, eles precisam da gente lá.

Mas para isso vamos ter que falar a língua deles: "projetos burocráticos"'.

Por outro lado, B define uma situação por meio de um processo de enquadramento em que o rap é apresentado como excluído da programação da Virada Cultural em detrimento de outros estilos musicais que não representam a periferia de Curitiba. Este processo visa construir um quadro de ação coletiva: "Quero Rap na Virada", que, por meio de um abaixo-assinado eletrônico, será comunicado às autoridades locais "para mostrarmos a força que a periferia representa na cidade de Curitiba".

Na construção de seu quadro de ação coletiva, B produz "quadros de diagnóstico", "quadros de prognóstico" e "quadros motivacionais" que podem ser assim classificados:

a) Quadro de diagnóstico: "Esta campanha é para você que já está cansado de não ouvir a música que lhe representa no Festival de Cultura denominado 'Virada Cultural' que aconteceu nos últimos 3 anos na sua própria cidade, Curitiba".

b) Quadro de prognóstico: "Por este motivo nós convocamos vocês, para exigir que 0 RAP seja representado em um dos shows principais do evento. Para isso iremos desenvolver um abaixo-assinado online, para mostrarmos a força que a periferia representa na cidade de Curitiba". c) Quadros motivacionais: "Chamem seus amigos, chamem seus vizinhos! ASSINEM O ABAIXO-ASSINADO, e vamos conquistar nosso espaço".

A ação de B é motivada por uma restrição política e não por uma oportunidade. Todo o processo de enquadramento será feito a partir desta restrição, visando assim revelar um conflito e um confronto que se dará por meio de um posicionamento individual articulado coletivamente.

0s enquadramentos ("Falar a língua deles" e "lá dentro do sistema") mobilizados por A para construir seu quadro de ação coletiva ("Projetos burocráticos") não excluem os enquadramentos anteriormente mobilizados por B no processo que culminou no quadro da ação coletiva "Quero Rap na Virada".

A questiona a estratégia de ação de B, e não sua ação propriamente dita e suas motivações. A disputa dos enquadramentos não se dá nos quadros de prognóstico nem de motivação, mas nos quadros de prognóstico. A considera o recurso do abaixoassinado pouco eficaz, dado o nível de burocracia existente para a obtenção de recursos culturais.

Depois dessa interação, não houve mais postagens de B que, por meio da proposição de um abaixoassinado, foi quem motivou $\mathbf{A}$ a interagir e iniciar um segundo processo de mobilização. Pode-se supor, de uma maneira apenas especulativa, que este "silêncio" de B indica uma discordância com 
a proposta de A. Tal suposição está embasada em uma percepção por meio de entrevistas e letras de rap da existência de uma profunda desconfiança do sistema político, compartilhada por muitos atores do hip-hop. Portanto, alinharse ao poder para alguns atores do hip-hop soa como traição ao movimento.

\section{Considerações Finais}

A operacionalização de um método propositivo de análise de enquadramentos construídos a partir de pressupostos da Teoria da Mobilização Política, que chamamos de análise de mobilização de quadros, produziu, ao longo de seu processo, uma base analítica tal que permite fazer algumas considerações.

Foi possível perceber dois quadros de ação coletiva em jogo. A investe na construção "projetos burocráticos", enquanto B propõe a construção "Quero Rap na Virada". 0 abaixo-assinado é 0 único recurso disponível no repertório de $\mathbf{B}$, o que incide sobre 0 enquadramento da ação. Desse modo, entendemos que B empreende uma campanha para inclusão do hip-hop no evento da Fundação Cultural de Curitiba.

Por sua vez, A procura explorar a oportunidade aberta pelos editais, que exige uma concessão de $\mathbf{B}$ ao poder público. "Projetos burocráticos" assume, então, uma função de enquadramento, ao sugerir a utilização de um repertório do adversário, cujas práticas impedem, na visão de $\mathbf{B}$, a inclusão do hip-hop na cena cultural, e apontar para a necessidade de uma ação coletiva dos atores do hip-hop curitibano capaz de operar de acordo com o funcionamento dos mecanismos burocráticos de gestão cultural.

Reitera-se 0 caráter propositivo deste trabalho evitando colocar-se como um método que poderia simplesmente ser aplicado sobre 0 objeto da observação. Bem distante desta possibilidade, 0 artigo é mais uma porta de entrada para a Teoria da Mobilização Política, através da discussão de alguns conceitos e autores, e uma tentativa de vivenciar esta experiência teórica empiricamente e de convidar outros pesquisadores para esta experiência e provocá-los para pensar sobre ela, criticá-la, apontar limites e deficiências.

Cabe dizer ainda que a elaboração de quadros da ação coletiva não se reduz a um processo impositivo de um grupo ou ator sobre outro. Mobilizar é um processo comunicacional, mas com uma fundamental dimensão interativa e simbólica constantemente operada por todos aqueles envolvidos em um processo de mobilização. Não por acaso, Snow \& Benford (2000, p.625) consideram que todos os atores que se engajam em uma ação coletiva estão envolvidos em uma disputa política de significação. Para eles, nenhum ativista é capaz de construir e impor a outro uma versão da realidade que lhe apetece, pois "há uma variedade de desafios confrontando todos aqueles que se dedicam às atividades de enquadramento necessárias para que uma ação coletiva possa acontecer". 


\section{Referências}

BENFORD, Robert D.; SNOW, David A. Framing

Processes and Social Movements: An Overview and

Assessment. Annual Review of Sociology, v. 26, 2000, pp. 611-639.

CEFAÏ, Daniel. Pourquoi se mobilise-t-on? Les thérories de l'action collective. Paris, La Découverte/M.A.U.S.S, 2007.

GAMSON, William. Talking politics. Cambridge/Nova

York/Melbourne, Cambridge University Press, 1992.

GAMSON, William; MEYER, David. Framing of political opportunity. In: McADAM, Doug; McCARTHY, John D.; ZALD, Meyer N. (orgs). Comparative perspectives on social movements: political opportunities, mobilizing structures, and cultural framings. Cambridge: Cambridge University Press, 1996, p. 275-290.

GOFFMAN, Erving. Os quadros da experiência social: uma perspectiva de análise. Petrópolis, Rio de Janeiro: Vozes, 2011.

MAIA, Rousiley Celi Moreira. Internet e esfera civil: limites e alcances da participação política. In: GOMES, Wilson; MAIA, Rousiley C. M.; MARQUES, Francisco J. A. (Orgs.). Internet e participação política no Brasil. Porto Alegre: Sulina, 2011.

McADAM, Doug; McCARTHY, John D.; ZALD, Meyer N. (orgs). Comparative perspectives on social movements: political opportunities, mobilizing structures, and cultural framings. Cambridge: Cambridge University Press, 1996

McADAM, Doug; TARROW, Sidney; TILLY, Charles. Para mapear o confronto político. Lua Nova, 2009, n.76, pp. $11-48$.

MENDONÇA, Ricardo Fabrino \& SIMÕES, Paula Guimarães. Enquadramento: diferentes operacionalizações analíticas de um conceito. Revista Brasileira de Ciências Sociais, 2012, vol. 27, pp. 187-201.
PRUDENCIO, Kelly Cristina de Souza. Mobilizar é comunicar estruturas interpretativas: apontamentos para discussão e pesquisa sobre a comunicação dos atores coletivos. In: $21^{\circ}$ Encontro Anual da Compós, Juiz de Fora (MG), Jun. 2012.

PRUDENCIO, Kelly; SILVA JUNIOR, José Geraldo. Curitiba também tem periferia: a comunicação multiterritorial do hip-hop. Contemporânea, Rio de Janeiro, v.1, n.21, 2013.

SILVA JUNIOR, José Geraldo. Conexão e ação: a utilização estratégica da internet pela "Marcha das Vadias" para mobilização social e ação coletiva no espaço virtual e no território urbano. In: A mobilização social no contexto político e eleitoral. PANKE, Luciana; MACED0, Roberto Gondo; ROCHA, Daniele (Orgs.). Capivari (SP): Nova Consciência (2013).

SNOW, David A.; ROCHFORD, E. Burke; WORDEN, Steven K.; BENFORD, Robert D.. Frame Alignment Processes, Micromobilization, and Movement Participation. American Sociological Review, v.51, n. 4, 1986, pp. 464-481.

TARROW, Sidney. 0 poder em movimento.

Movimentos sociais e confronto político. Petrópolis: Vozes, 2009. 


\section{Political communication in} micromobilizations on the Internet concerning the hip hop in Curitiba

\section{Abstract}

The article presents a methodological perspective for political mobilization on the Internet, based on the theory of political mobilization or political processes (MCADAM, McCarthy and Zald, 2008; Tarrow 2009, Gamson, 1990), specifically when dealing with processes of "frame alignment". The intention is to provide some theoretical background for the observation of such phenomena, by presenting an example of micromobilization on the Internet by groups and individuals connected to hip hop in Curitiba. We understand that the process of framing collective action in digital media constitutes a work of political communication.

\section{Keywords}

Political mobilization. Framing. Internet. Hip hop.

\section{La comunicación política de las} micromovilizaciones en internet desde la observación de hip hop en Curitiba

\section{Resumen}

Este artículo presenta una perspectiva analítica para la movilización política en Internet, basada en la teoría de la movilización política o los procesos políticos (McAdam, McCarthy y Zald, 2008; Tarrow 2009, Gamson, 1990), especialmente cuando se trata de los procesos de "alineación de marcos ". Con él, la intención es ofrecer algún margen teórico para la observación de estos fenómenos, con un ejemplo de micromovilización en Internet por grupos e individuos vinculados al hip hop en Curitiba. Creemos que el proceso de elaboración de la acción colectiva en los medios digitales si se trata de un trabajo de comunicación política.

\section{Palabras clave}

Movilización política. El encuadre. Internet. Hip hop. 


\section{Expediente}

A revista E-Compós é a publicação científica em formato eletrônico da Associação Nacional dos Programas de Pós-Graduação em Comunicação (Compós). Lançada em 2004, tem como principal finalidade difundir a produção acadêmica de pesquisadores da área de Comunicação, inseridos em instituições do Brasil e do exterior.

\section{E-COMPÓS I www.e-compos.org.br I E-ISSN 1808-2599}

Revista da Associação Nacional dos Programas de Pós-Graduação em Comunicação.

Brasília, v.18, n.2, maio/ago. 2015.

A identificação das edições, a partir de 2008, passa a ser volume anual com três números.

Indexada por Latindex I www.latindex.unam.mx

\section{CONSELHO EDITORIAL}

Alexandre Rocha da Silva, Universidade Federal do Rio Grande do Sul, Brasil Alexandre Farbiarz, Universidade Federal Fluminense, Brasil Ana Carolina Damboriarena Escosteguy, Pontifícia Universidade Católica do Rio Grande do Sul, Brasil

Ana Carolina Rocha Pessôa Temer, Universidade Federal de Goiás, Brasil Ana Regina Barros Rego Leal, Universidade Federal do Piauí, Brasil André Luiz Martins Lemos, Universidade Federal da Bahia, Brasil Andrea França, Pontifícia Universidade Católica do Rio de Janeiro, Brasil Antonio Carlos Hohlfeldt, Pontifícia Universidade Católica do Rio Grande do Sul, Brasil

Arthur Ituassu, Pontifícia Universidade Católica do Rio de Janeiro, Brasil Álvaro Larangeira, Universidade Tuiuti do Paraná, Brasil Ângela Freire Prysthon, Universidade Federal de Pernambuco, Brasil César Geraldo Guimarães, Universidade Federal de Minas Gerais, Brasil Cláudio Novaes Pinto Coelho, Faculdade Cásper Líbero, Brasil Daisi Irmgard Vogel, Universidade Federal de Santa Catarina, Brasil Daniela Zanetti, Universidade Federal do Espírito Santo, Brasil Denize Correa Araujo, Universidade Tuiuti do Paraná, Brasil Eduardo Antonio de Jesus, Pontifícia Universidade Católica de Minas Gerais, Brasil

Eduardo Vicente, Universidade de São Paulo, Brasil

Elizabeth Moraes Gonçalves, Universidade Metodista de São Paulo, Brasil Erick Felinto de Oliveira, Universidade do Estado do Rio de Janeiro, Brasil Francisco Elinaldo Teixeira, Universidade Estadual de Campinas, Brasil Francisco Paulo Jamil Almeida Marques, Universidade Federal do Ceará, Brasil Gabriela Reinaldo, Universidade Federal do Ceará, Brasil Gisela Grangeiro da Silva Castro, Escola Superior de Propaganda e Marketing, Brasil

Goiamérico Felício Carneiro Santos, Universidade Federal de Goiás, Brasil Gustavo Daudt Fischer, Unisinos, Brasil

Herom Vargas, Universidade Municipal de São Caetano do Sul, Brasil
Itania Maria Mota Gomes, Universidade Federal da Bahia, Brasil Janice Caiafa, Universidade Federal do Rio de Janeiro, Brasil Jiani Adriana Bonin, Universidade do Vale do Rio dos Sinos, Brasil José Afonso da Silva Junior, Universidade Federal de Pernambuco, Brasil José Luiz Aidar Prado, Pontifícia Universidade Católica de São Paulo, Brasil Kati Caetano, Universidade Tuiuti do Paraná, Brasil

Lilian Cristina Monteiro França, Universidade Federal de Sergipe, Brasil

Liziane Soares Guazina, Universidade de Brasília, Brasil Luíza Mônica Assis da Silva, Universidade de Caxias do Sul, Brasil Luciana Miranda Costa, Universidade Federal do Pará, Brasil Malena Segura Contrera, Universidade Paulista, Brasil Marcel Vieira Barreto Silva, Universidade Federal da Paraíba, Brasil Maria Ogécia Drigo, Universidade de Sorocaba, Brasil Maria Ataide Malcher, Universidade Federal do Pará, Brasil Maria Clotilde Perez Rodrigues, Universidade de São Paulo, Brasil Maria das Graças Pinto Coelho, Universidade Federal do Rio Grande do Norte, Brasil

Mauricio Ribeiro da Silva, Universidade Paulista, Brasil

Mauro de Souza Ventura, Universidade Estadual Paulista, Brasil

Márcio Souza Gonçalves, Universidade do Estado do Rio de Janeiro, Brasil Micael Maiolino Herschmann, Universidade Federal do Rio de Janeiro, Brasil Mirna Feitoza Pereira, Universidade Federal do Amazonas, Brasil Nísia Martins Rosario, Universidade Federal do Rio Grande do Sul, Brasil Potiguara Mendes Silveira Jr, Universidade Federal de Juiz de Fora, Brasil Regiane Ribeiro, Universidade Federal do Paraná, Brasil Rogério Ferraraz, Universidade Anhembi Morumbi, Brasil Rose Melo Rocha, Escola Superior de Propaganda e Marketing, Brasil Rozinaldo Antonio Miani, Universidade Estadual de Londrina, Brasil Sérgio Luiz Gadini, Universidade Estadual de Ponta Grossa, Brasil Simone Maria Andrade Pereira de Sá, Universidade Federal Fluminense, Brasil Veneza Mayora Ronsini, Universidade Federal de Santa Maria, Brasil Walmir Albuquerque Barbosa, Universidade Federal do Amazonas, Brasil

\section{COMISSÃO EDITORIAL}

\section{Cristiane Freitas Gutfreind}

Pontifícia Universidade Católica do Rio Grande do Sul, Brasil

Irene Machado

Universidade de São Paulo, Brasil

Jorge Cardoso Filho

Universidade Federal do Reconcavo da Bahia, Brasil

Universidade Federal da Bahia, Brasil

\section{EQUIPE TÉCNICA}

ASSISTENTE EDITORIAL I Márcio Zanetti Negrini

REVISÃO DE TEXTOS I Press Revisão

EDITORAÇÃO ELETRÔNICA I Roka Estúdio

CONTATO I revistaecompos@gmail.com
COMPóS I www.compos.org.br

Associação Nacional dos Programas de Pós-Graduação em Comunicação

Presidente

Edson Fernando Dalmonte

Programa de Pós-Graduação em Comunicação

e Cultura Contemporânea - UFBA

edsondalmonte@uol.com.br

Vice-presidente

Cristiane Freitas Gutfreind

Programa de Pós-Graduação em Comunicação Social - PUC-RS cristianefreitas@pucrs.br

Secretário-Geral

Rogério Ferraraz

Programa de Pós-Graduação em Comunicação

Universidade Anhembi Morumbi

rogerioferraraz@anhembimorumbi.edu.br 